\title{
Global Heritage: Worlds Apart?
}

Cornelia Kleinitz, Rock Art Research Institute (RARI), University of the Witwatersrand, Johannesburg, South Africa; Department of Egyptology and Northeast African Archaeology, Institute of Archaeology, Humboldt-Universität zu Berlin, Berlin, Germany E-mail: cornelia.kleinitz@staff.hu-berlin.de

Claudia Näser, Department of Egyptology and Northeast African Archaeology, Institute of Archaeology, Humboldt-Universität zu Berlin, Berlin, Germany

Stefan Altekamp, Department of Classical Archaeology, Institute of Archaeology, Humboldt-Universität zu Berlin, Berlin, Germany

Archaeological sites are charged locations; they are spaces sui generis in the cultural landscape. Their declaration alone-sometimes, but not necessarily accompanied by distinct physical markings and a change in legal status - can lead to the abrupt termination of previous and alternative uses. The designation, development and maintenance of archaeological sites involve diverse interest groups and stakeholders with potentially very different standpoints. Stakeholders include individuals and groups who are physically present at the archaeological sites, such as local residents, landowners and entrepreneurs, academic experts and visitors of all types, but also parties who have never necessarily 'touched the ground', such as policymakers operating on local, regional and national level, representatives of international tourism companies, as well as members of academic funding bodies and heritage organisations. Consequently, the production, appropriation and consumption of archaeological heritage spaces are marked by the interplay of local, regional, national and, increasingly, global actors and institutions.

Whereas their status alone can turn archaeological sites into the focus of manifold political, economic and cultural expressions and an arena of multiple social practices, additionally they are often subjected to severe physical transformations by individual interest groups. Although archaeologists and other heritage professionals usually enjoy privileged access to sites for the sake of research, preservation and presentation, the production, appropriation and consumption of archaeological spaces are not governed primarily by the properties which qualify a site in scientific terms, eg. as a testimony of a specific era or culture. Their significance, instead, evolves from their 
specific position in the present-day cultural landscape, the degree of interest they attract from different stakeholder groups and the functions these groups assign to these spaces. The historical narratives that are constructed from archaeological heritage spaces in the scholarly debate and tourist promotion literature are semantic-and contested-realities, which emerge "from a network of political interests and scholarly intertextuality that dominate, structure, and finally imply a socio-cultural reality to correspond with our imaginative texts" (Slyomovics 1989:140).

Today, archaeological sites form a cultural, economic and symbolic resource on a global scale. However, as Françoise Choay (1995:298) maintains, "the historical monument is no cultural universal" but a highly specific notion and the product of Western constructions of cultural identities from early modernity onwards. In many regions of the world the concept of the 'archaeological site', as well as the value systems and the expert practices connected to these spaces, are ideational imports, which were introduced as part of the colonial and imperialist projects of the 19th and 20th centuries. The global homogenisation of these concepts was greatly accelerated by the World Heritage scheme introduced through the eponymous UNESCO convention in $1972 .{ }^{1}$ In the past 40 years, the label World Heritage has become a globally recognised brand. In many contexts it is considered "the benchmark for cultural significance" (Lee Long 2005:65), thereby marginalising other concepts and operations of assigning and representing such significance. Like postcolonial archaeologies or mass tourism, the concept of World Heritage is a manifestation of globalisation, but also a driver for its further development.

In the ever-growing global intertwining and 'densification' of relations between societies, institutions and individuals, local worlds are more and more measured against value sets which have global, as opposed to local, referents. This is also true for the production and consumption of archaeological sites. Local residents in the Global South experience the Global North through the behavioural patterns of tourists, archaeologists and other heritage professionals. The very idea of a commonly shared global heritage is increasingly questioned through recognition of the wildly unequal power relations characterising the encounters of different groups of stakeholders in many of the processes surrounding archaeological heritage spaces in these non-Western contexts. Strategies towards heritage under such globalised conditions are often as violent as their colonial predecessors (Meskell 2000). The complex interactions of the divergent stakeholders, their claims to, and appropriations of, archaeological sites under these premises formed the focus of the research group 'Archaeotopia', which was founded by the editors of the present volume within the Berlin Cluster of Excellence TOPOI in 2009..$^{2}$ Archaeotopia's particular focus is on instances in which archaeology and the notion of an archaeological 
heritage site are ideational imports from the Western world, as outlined above, but adapted and applied in manifold ways. To further this research concern, we organised a conference at Humboldt-Universität zu Berlin in July 2012, ${ }^{3}$ which brought together representatives of several disciplines, including archaeology, anthropology, sociology, social geography, art history, urban planning, museum studies and heritage studies, who discussed the issue from their respective perspectives. Part of the meeting was devoted to archaeological case studies from the main study region, namely Northern Africa and the Middle East. The present volume unites these case studies, as well as-due to its timeliness-an additional contribution on the destruction of heritage spaces in Mali.

This volume owes a lot to the intense discussions during the conference. Its title, "Global heritage - worlds apart. The cultural production, appropriation and consumption of archaeological heritage spaces," suggested that while archaeological heritage has become a global concept, positions of different stake-holders-even when they are physically co-present at a site-are often 'worlds apart'. This dictum was examined in detail by the conference participants, and as a consequence the full stop behind the main title line was replaced by a question mark in the title of the present volume and editorial. In fine-grained analyses, its seven contributions investigate a wide array of scenarios in which a multitude of stakeholders, individuals and groups, locals and non-locals, enter into complex interactions centering on the production, appropriation and consumption of archaeological heritage spaces. The authors explore the motivations, scopes and regulating factors of these interactions and how the concept of heritage as a globally valid category of valorisation is used in the discourses of the different stakeholders. Moving away from essentialist notions of heritage, the authors acknowledge and embrace the complex realities and intricate mechanisms, as well as the particular performances, played out in these scenarios-including those of the researchers themselves. Discussions revolve around the issues of participation and entanglement, but also around contradictory and conflictive approaches and claims.

Barbara Kirshenblatt-Gimblett (2005) has defined heritage as a mode of cultural production that has recourse to the past and produces something new. Heritagisation, however, as acted out under the label of World Heritage can also be seen as a process of turning lived practices and lived-in materialities into heritage, transposing them into an alienated and alienating heritage sphere with its own standards and operations, which are put at the disposal of the worldwide 'heritage community'. The increasing diffusion of cultural practices and value systems as a consequence of processes of globalisation does not necessarily result in their recognition, but can also evoke categorical confrontation, and fuel contradiction and conflict. Valorisation may provoke rejection as much as approval, and the appropriation 
of archaeological spaces as World Heritage by some stakeholders may lead to processes of alienation and strategies of re-appropriation or dissociation by others. The papers assembled in this volume explore different trajectories of such processes. A particular focus is on conflictive situations, which may arise from competition over the appropriation and exploitation of the resources connected to, or mobilised through, archaeological heritage spaces - up to the point where the destruction of their materiality is turned into a resource itself, constituting an extreme form of their exploitation for the gain of cultural capital. Heritage professionals, as well as the members of 'the public', appear helpless in the face of situations in which individual groups of stakeholders claim their rights over heritage, but transfer it into positions that diverge markedly from common preservationist standpoints, eg. by destroying archaeological sites or by taking them hostage (cf. Kleinitz and Näser 2013). Nonetheless, such scenarios can still be understood analytically as a direct consequence of the global promotion of the heritage concept of Western coinage with specific stakeholders "actively select[ing] particular global ideas, processes and fora to consolidate and support their arguments" (Lee Long 2005:64).

In sum, the contributions to this volume highlight that the production of (archaeological) heritage spaces transgresses any set mechanism and can hardly be orchestrated by the top-down application of normative rules, globally standardised procedures or sanctions put into action by international expert bodies on the basis of 'universal' principles. Inversely, attempts to accommodate all the demands of potential stakeholder groups through an extended platform of discursive devices are also demonstrated to be a benign illusion. While the quality and impact of heritage management increases significantly with an awareness and acceptance of the diversity in attitudes and interests, raising the potential for inclusive decision making does not necessarily coincide with commonly agreed results. The case studies united in this volume describe in unison a reality in which conflict is resolved by power. In this they vividly illustrate the ambivalence of the concept of World Heritage, as oscillating between a historicised utopia and a moral appeal for global sharing and mutual benefit, and the manifold tensions that arise from the multitude of unresolved entanglements on the ground.

\section{Acknowledgments}

The conference "Global heritage - worlds apart. The cultural production, appropriation and consumption of archaeological heritage spaces," organised by the editors of the present volume, was held under the auspices of the Berlin Excellence Cluster 264 "TOPOI - The Formation and Transformation 
of Space and Knowledge in Ancient Civilizations", and hosted by Humboldt-Universität zu Berlin on 6 and 7 July 2012. The logistic and financial support of TOPOI is gratefully acknowledged. We would particularly like to thank Kerstin P. Hofmann for her intellectual commitment and invaluable support throughout the inception and research phases of the project 'Archaeotopia', and the preparation of the conference.

\section{Notes}

1. http://whc.unesco.org/en/conventiontext/ (last accessed on 25/10/2013).

2. http://www.topoi.org/feature/archaeotopia/, http://www.topoi.org/project/topoi-1-72/, http:// www.topoi.org/project/c-3-5/ (all last accessed on 25/10/2013).

3. http://www.topoi.org/event/global-heritage-worlds-apart-the-cultural-production-appropriation-and-consumption-of-archaeological-heritage-spaces/ (last accessed on 25/10/2013).

\section{References}

Choay, F.

1995. Sept propositions sur le concept d'authenticité. Seven Propositions on the Concept of Authenticity. In Nara Conference on Authenticity in Relation to the World Heritage Convention, Nara, Japan, 1-6 November 1994: Proceedings, edited by K. E. Larsen, pp. 297-300. UNESCO, Paris.

Kirshenblatt-Gimblett, B.

2005. From Ethnology to Heritage: The Role of the Museum. SIEF Keynote lecture, Marseilles, 28 April 2004. http://www.nyu.edu/classes/bkg/web/ SIEF.pdf. Accessed 10 November 2013.

Kleinitz, C., and C. Näser

2013. Archaeology, Development and Conflict: A Case Study from the African Continent. Archaeologies 9(1):162-191.

Lee Long, D.

2005. The Constitution and Mechanics of the 'Scales' of Heritage: Socio-political Dimensions. Papers from the Institute of Archaeology 16:59-71.

Meskell, L.

2000. The Practice and Politics of Archaeology in Egypt. In Ethics and Anthropology. Facing Future Issues in Human Biology, Globalism and Cultural Property, edited by A.-M. Cantwell, E. Friedlander, and M. L. Tramm, pp. 146-169. Annals of the New York Academy of Sciences 925, New York.

Slyomovics, S.

1989. Cross-Cultural Dress and Tourist Performance in Egypt. Performing Arts Journal 33/34:139-148. 